\title{
Challenges of NVH TeSting AND ANALysis OF ELECTRIC MOTORS
}

\author{
Davi Machado Cury ${ }^{1}$, César Abrahão Pereira Melo ${ }^{1}$, Cássio T. Faria ${ }^{2}$, André de Oliveira $^{1}$ \\ ${ }^{1}$ Siemens Industry Software Ltda, Brazil \\ ${ }^{2}$ Siemens Industry Software NV, Belgium
}

E-mails: $\frac{\text { davi.cury@ } @ \text { siemens.com, cesarabrahao.melo@ siemens.com, }}{\text { cassio.faria@ siemens.com }}, \underline{\text { andre.oliveira1@ } @ \text { siemens.com }}$

\begin{abstract}
One of the major trends in mobility nowadays is the usage of electric motors in vehicles, encouraged by governments worldwide in search to decrease pollutant emissions and reduce dependence on fossil fuels. This has introduced a whole new challenge for the noise and vibration attributes on motor design, since although there is no combustion phenomena and the gearbox is greatly reduced or non-existent in electric vehicles, new acoustical phenomena happens, such as structural vibrational modes of the stator, or power electronics controller frequency operation. Usually the noise is at higher frequencies than what is experienced on internal combustion engines, which sometimes can lead to a worse acoustic perception of the product. This paper present some of the main noise sources of common electric inner-rotor motor design, and elaborate on typical challenges and particularities of its experimental $\mathrm{NVH}$ (Noise, Vibration and Harshness) test and analysis, in comparison to what is common practice on ICE (Internal Combustion Engine) testing and instrumentation.
\end{abstract}

\section{INTRODUCTION}

In the past few years Electric Vehicles (EVs) increased their popularity thanks to governmental incentives, technological advances in energy storage systems and more awareness on environmental impacts [1]. In addition to a decrease of urban pollution, electric mobility reduces oil dependence with consequent economic benefits in terms of price stability [2] and lower running costs [3]. However, the share of electric vehicles (EVs) in the automotive sector is still negligible in confront of Internal Combustion Engine (ICE) vehicles mainly due to their limited mileage. Therefore various solutions are developed to increase EVs autonomy, namely by improving the global efficiency and minimizing the components weight and cost.

The Brazilian market of EVs or Hybrid EVs is still quite small, with just around seven thousand vehicles on the streets, and 2017 sales just above three thousand units. This is mainly due to high prices and high taxes (higher than seen ICE vehicles counterparts). This scenario may change with new policies to lower taxes on EVs and HEVs [4]. Recent studies indicate that Brazil has the potential to sell 150 thousand units per year [5] [6]. 
Much has been said about the main challenges that electric vehicles pose to NVH, such as the more preeminent presence of wind and tire noise inside the cabin, since there is no engine combustion noise to mask it [7]. The focus of this paper are the noises that the electric motor itself produce.

\section{ELECTRIC MOTOR OPERATION}

The work principle of the electric motor is to convert electromagnetic energy into mechanical energy. This is usually achieved through a stator (fixed component) - rotor (rotating component) model design, in which both components have magnetic fields, and the interaction between these fields causes the rotor to spin with a certain torque and velocity, which consequently turns the motor shaft. These fields can be electrically produced through electromagnets, induced by other magnetic fields, or be constant, through permanent magnetic materials.

The ability to predict the level of vibration and emitted acoustic noise enables designers to target a reduction of those attributes for any given machine topology. However this is no simple task, given that multiphysical nature of the problem. Figure 1 below illustrates the different aspects of the physical process of the problem.

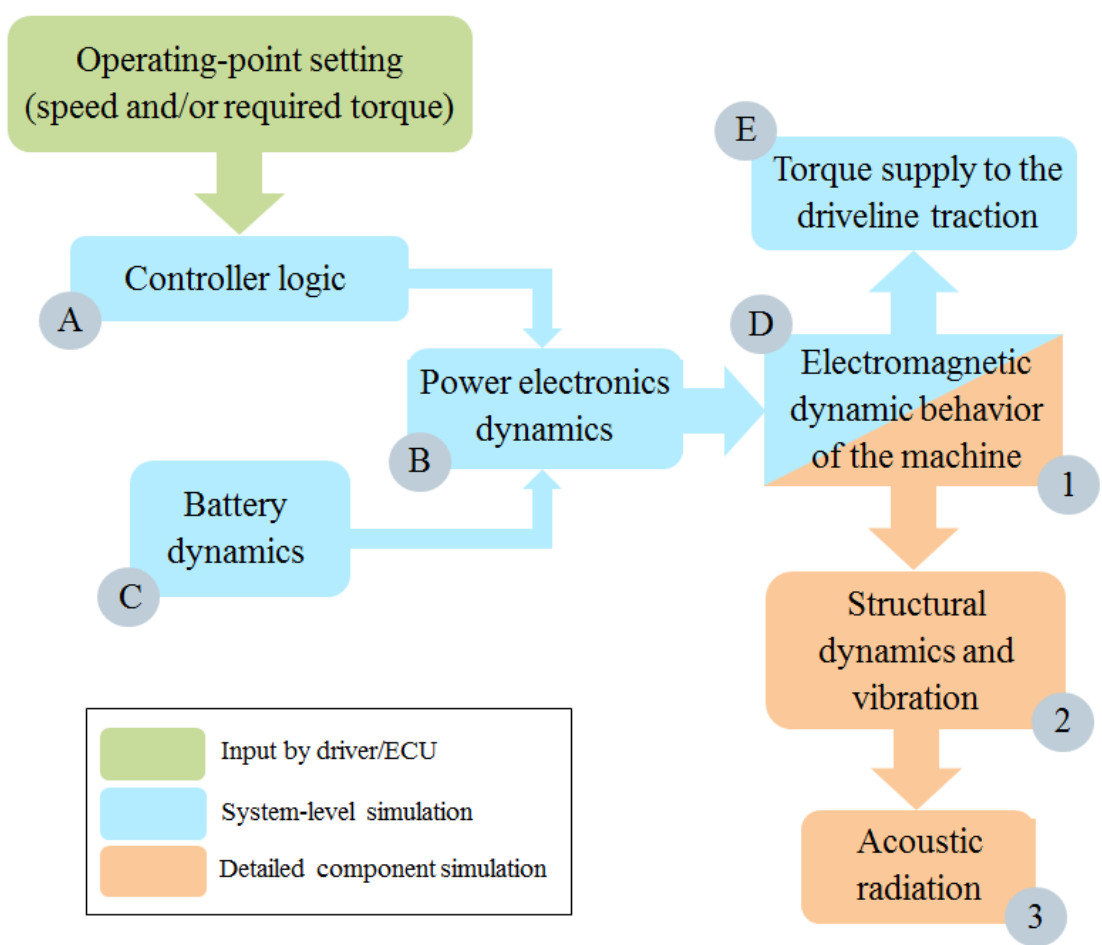

Figure 1. Multiphysical process of electrical machines operating in an automotive driveline

In the figure above, the commands from the driver and/or and vehicle electronic control unit (ECU) drives a machine-level control logic (A) to activate the system power electronics (B) that draws power from a battery supply (C) and energizes the electric machine (D) to, as mentioned before, supply the driveline (E) with a torque and speed. During the process sensory information is exchanged between the agents of this multiphysical and system-level process. 


\section{MAIN NOISE SOURCES IN ELECTRIC MOTORS}

There are several motor designs which have already been developed, and each design has its own acoustic and vibrational behavior, which should be considered depending on the application [8] [12]. But in all motors, the energy excitation which drives the driveline is the main signature of its acoustic and vibrational behavior.

The motor which will be discussed in this paper is a 3-Phased Alternate Current Permanent Magnet Synchronous Motors (AC-PMSM). The strategy to control their speed is through a Pulse Width Modulation (PWM) converter. In an AC-PMS Motor, electro-magnets are positioned around the stator with one of the poles of each electro-magnet directed to the center of the cylinder. They are supplied by windings across the stator that are connected to an AC supply to produce a rotating magnetic field on the stator. The rotor is made with permanent magnets, which creates a constant magnetic field that follows the rotating field of the stator at synchronous speed [9].

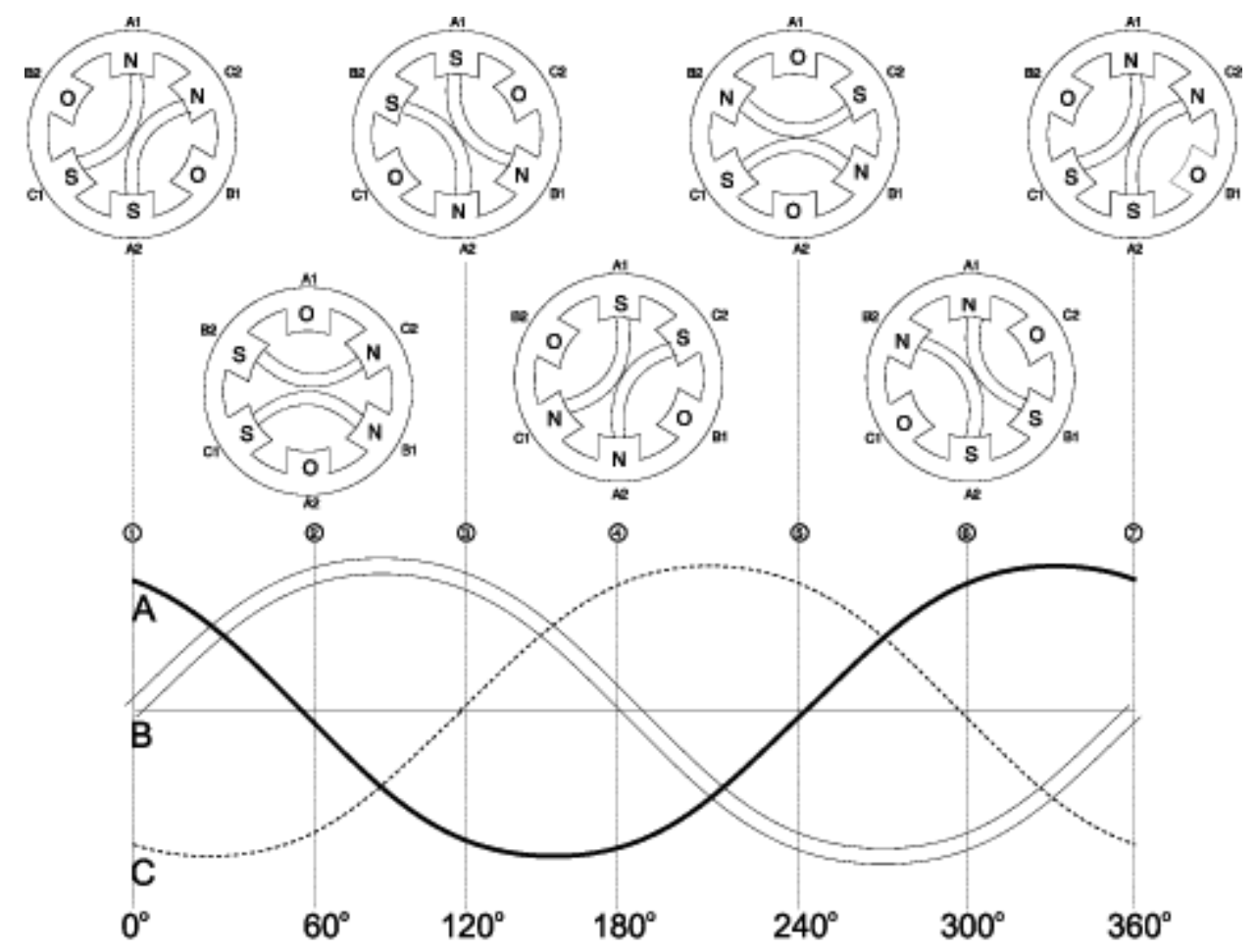

Figure 2 - Representation of how a 3-phased power supply to the stator produces a rotating magnetic field. Example of a stator with 6 poles [9]

The most common ICE engine type in Brazilian market is 4-cylinder, which gives a signature of main order 2 (two combustions per engine rotation) and its harmonic 4 (example: Figure 3 ). On electric motors, the signature is given by the electromagnetic excitations per motor rotation. Therefore, if the stator has 8 magnetic poles, and the stator coils are fed by a 3-phase power supply, for each full rotation there are 24 excitations, 8 for each phase, indicating a motor signature of main orders 8 and 24, and harmonic 48, with order 24 being the most preeminent (Figure 4). 


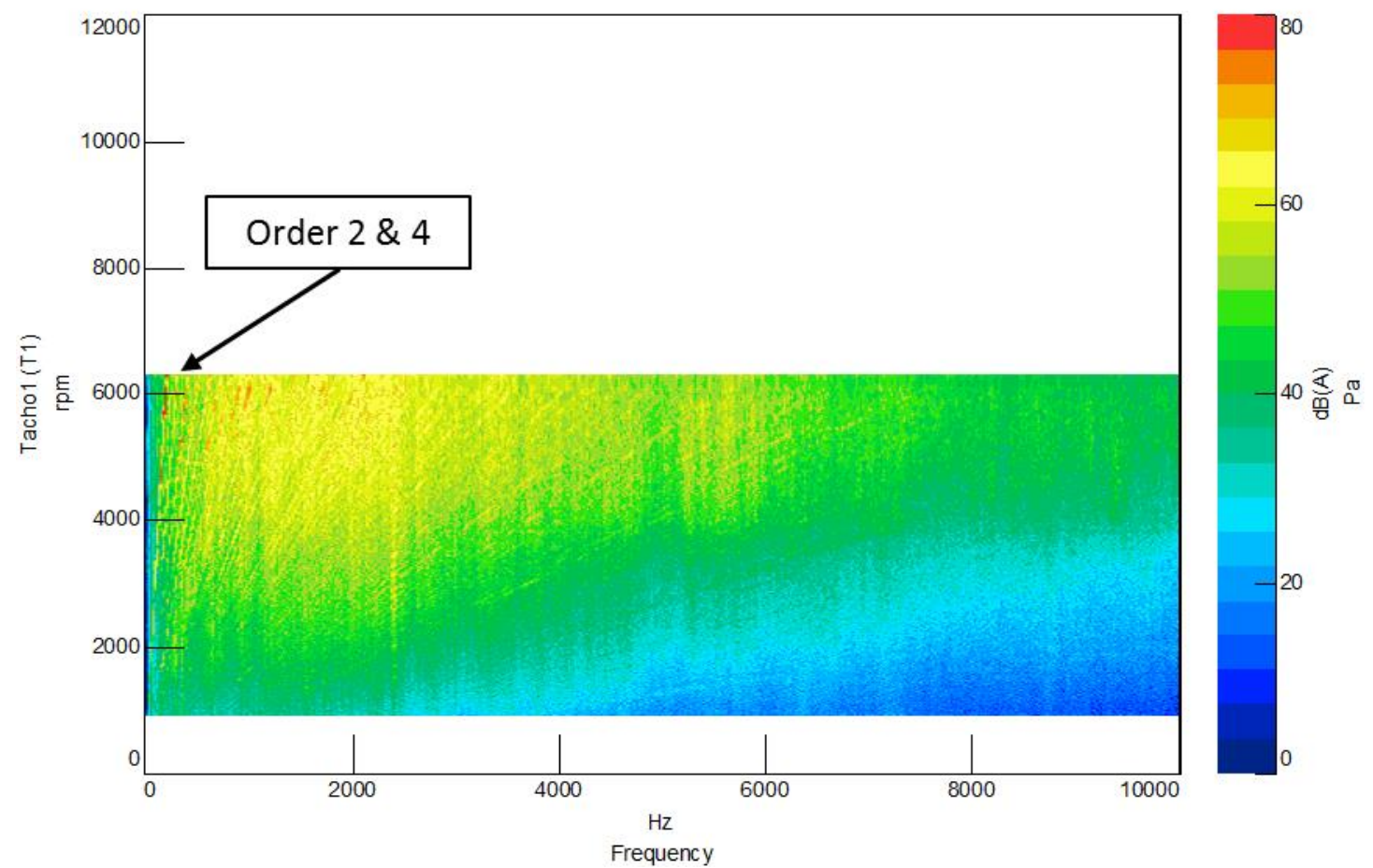

Figure 3 - Acoustic measurement colormap of a 4-cylinder ICE engine, and its main signature orders highlighted

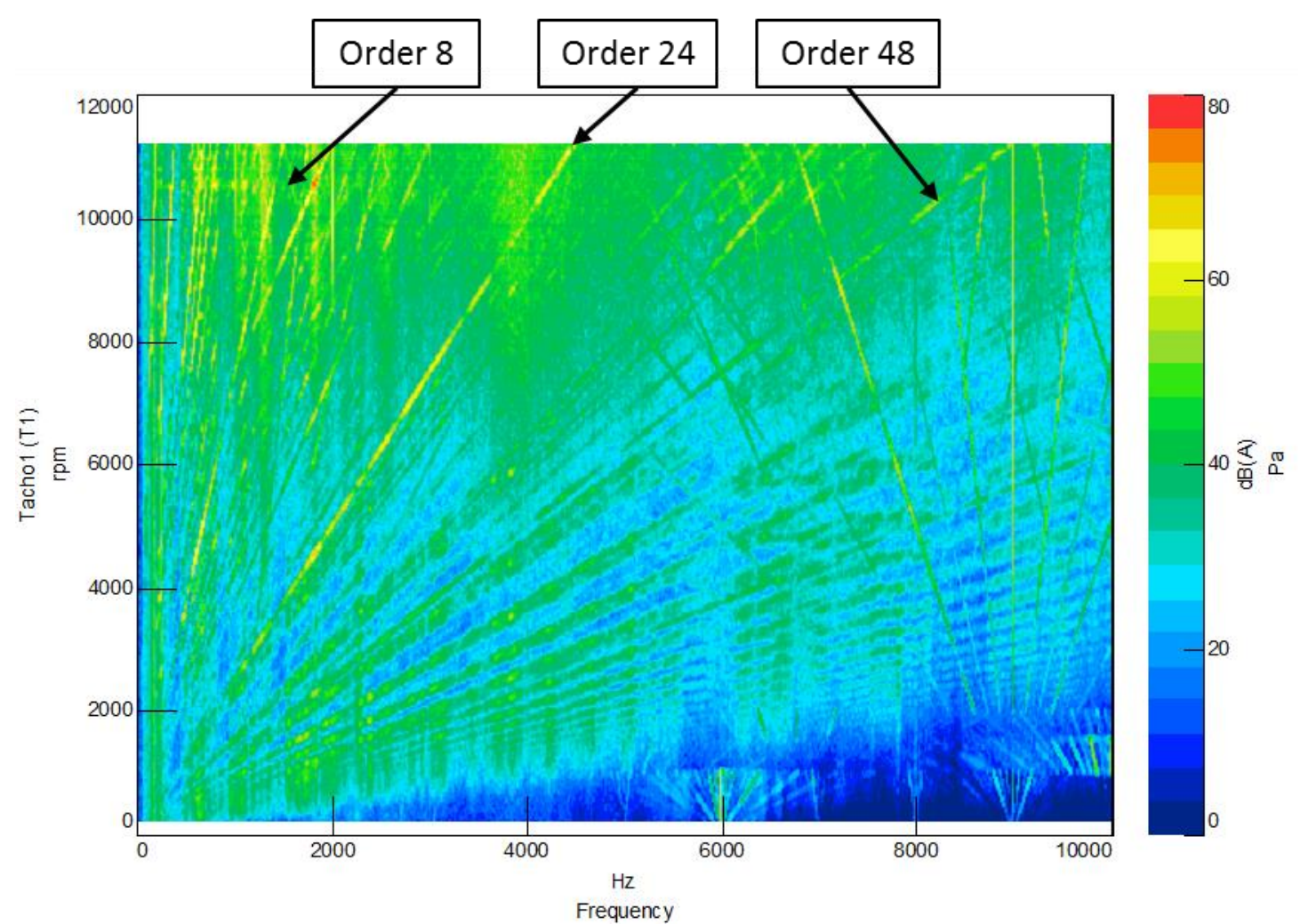

Figure 4 - Acoustic measurement colormap of an EV engine, and its main signature orders highlighted

The EM also has a broader operating range than the ICE. While ICE operating range is from idle speed (around $800 \mathrm{rpm}$ ) to engine cut-off (ex: 6000-6500 rpm), EM can operate on lower 
rotations to much higher than 6000rpm (200 to $11200 \mathrm{rpm}$ ). As a result, the operating frequency range of the motor can reach up to almost $9 \mathrm{kHz}$ (order $48 \times 11200 \mathrm{rpm} / 60 \mathrm{~s}=$ $8960 \mathrm{~Hz}$ ), much higher than what is seen in ICE. Although the EM show a lower overall pressure level through the colormap, this high frequency content with tonal behavior (separated harmonic frequencies radiating, as represented by the thin lines in Figure 4, in comparison to ICE "cloud" at higher rotations) can cause a worse sound quality perception of the machine.

Going back to Figure 1, the electromagnetic excitation of the machines produces tangential force components that deliver in driveline the usable torque from the machine (process from $\mathrm{D}$ to $\mathrm{E}$ in Figure 1); however this force build-up has a side effect that also produces radial force components. In inner-rotor electrical machines, most of the generated acoustic noise (block 3 in Figure 1) comes from structural vibration (block 2) due to the electromagnetic airgap forces acting on the stator (block 1) [10][11]. Other secondary sources have their contribution as well, such as the PWM converter and the rotor, which will be later be discussed, or motor unbalance, which will not be discussed in this work.

\subsection{STATOR}

As mentioned before, the stator vibration due to electromagnetic excitations is regarded as the main source of acoustic emissions of the electric motor [10] [11] [12]. Usually the stator concentrates most of the mass of the machine. Its construction is of a steel cylinder made of many thin laminations stacked together, which are insulated from one another with a resin, in order to prevent energy loss with eddy currents. Therefore, its vibrational behavior is not simple to predict in early design phase, but several studies were already performed to show how to create simulation models that perform a good correlation with test data [13] [14] [15] [16].

The electromagnetic excitations acting in such a wide frequency spectra means that the motor can operate in frequencies that matches frequencies of the natural modes of the stator. Therefore, a modal analysis was performed on the same motor of Figure 4, in order to identify these natural frequencies. This motor was excited with a shaker (LMS QSources High Frequency Shaker), positioned above the stator housing, and measured with accelerometers (PCB 356A24, 353B17 and 352A21) spread around the motor outer surface. The motor was fixed on a test bench, and had its rotor installed. Figure 5 shows the FRF SUM of all accelerometers, with a highlight on frequency band where stator mode shapes were identified. 


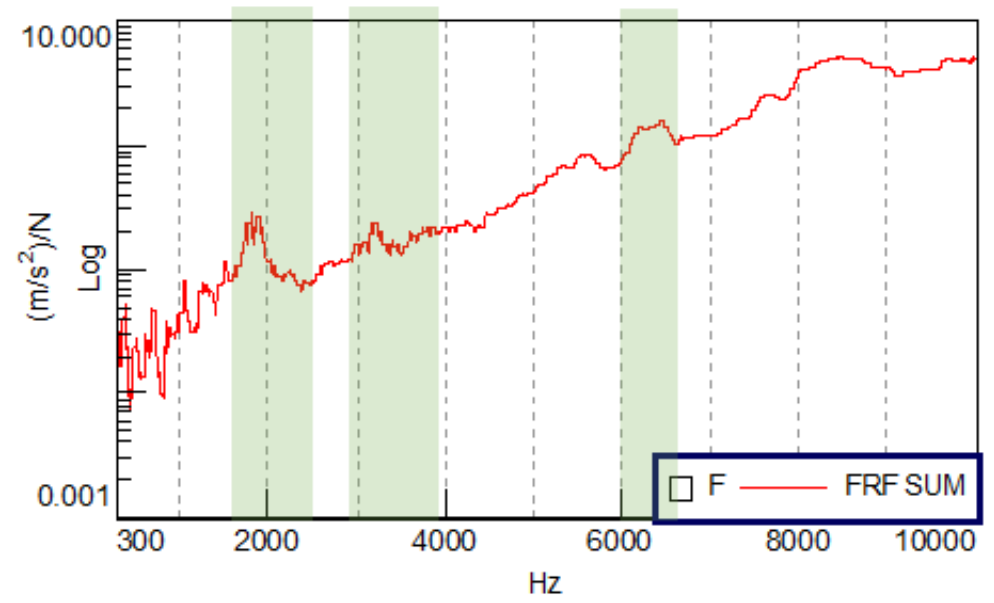

Figure 5 - FRF SUM of all accelerometers

\begin{tabular}{|c|c|c|}
\hline Modal Shape & Description & Frequency \\
\hline & Ovalization & $1600-2100 \mathrm{~Hz}$ \\
\hline Triangular & $2900-3900 \mathrm{~Hz}$ \\
\hline
\end{tabular}

Table 1 - Modal shapes of the motor around the stator housing

The frequency regions highlighted in Figure 5 showed modes with the same behavior of stator modes (as stated on bibliography and references), especially around the stator housing, shown in modal shapes of Table 1. This confirms the influence of the stator vibration on the whole motor vibration. These same frequency ranges show high acoustic level as well on Figure 4, which also confirms the influence of the stator vibrational behavior on overall acoustic behavior of the engine.

If the rotation speed is set so the main orders of the motor are at the same frequency of these modes, it is possible to observe how the acoustic pressure level rises. Figure 6 shows the frequency spectra of the motor with the rotation fixed at $2250 \mathrm{rpm}$, 
which makes the $48^{\text {th }}$ order to be around $1800 \mathrm{~Hz}$, in order to match with the natural frequency of the "ovalization" mode. Figure 7 shows the spectra at the fixed speed of $4500 \mathrm{rpm}$, so the $24^{\text {th }}$ order to be at $1800 \mathrm{~Hz}$. In both cases, this frequency is predominant over the other peaks.

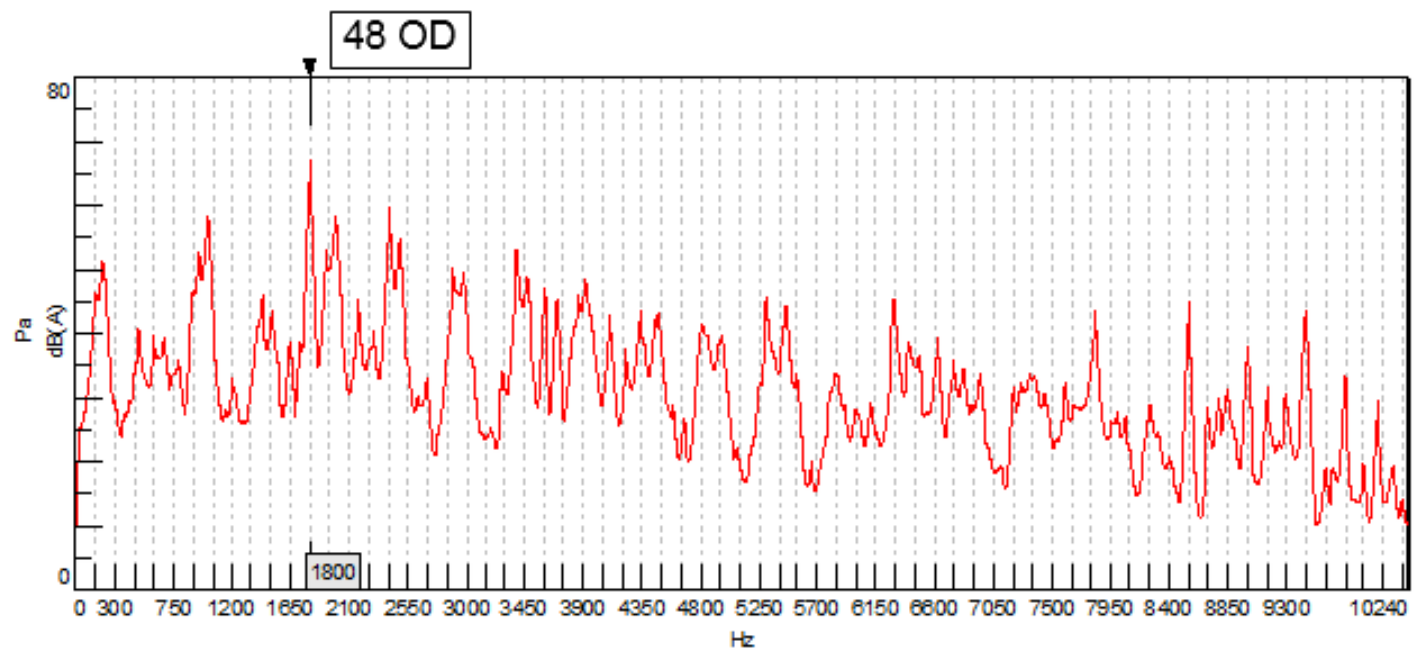

Figure 6 - Frequency spectra at fixed speed of $2250 \mathrm{rpm}$

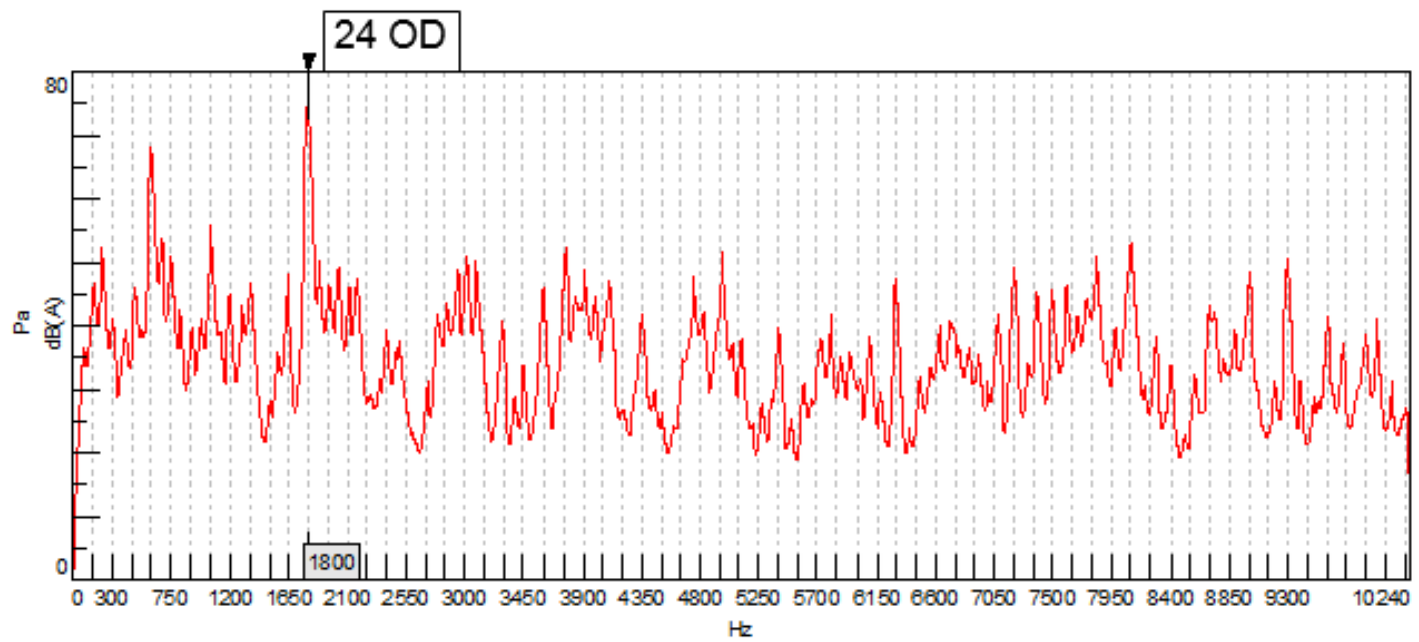

Figure 7 - Frequency spectra at fixed speed of $4500 \mathrm{rpm}$

For higher frequencies, the noise can be mitigated with the use of absorbing materials in the vehicle, but reducing noise in frequencies below $2 \mathrm{kHz}$ is not an easy task simply adding absorbing material. The best way to avoid the coupling between electromagnetic excitation and natural modes of the stator is to avoid working on the coupling rotations, by knowing beforehand through simulation the stator structural behavior.

\subsection{ROTOR}

Although the stator is the acoustic main source of the motor, the rotor should not be neglected, since this is the element that transmits torque and speed to the driveshaft, and it also have direct contact to the stator through the bearings. Past work has found 
that the rotor contributes on the overall damping of the structure, and that there is a mode which only appears when the rotor is attached to the stator, which involves axial bending of the stator together with a rotor bending, which called for more investigation [17]. Studies also have been made to define the best way to simulate the complex coupling between rotor and stator, which also indicated the aforementioned bending mode [18].

Instrumenting rotational components to perform operational measurements can be troublesome, with the need of slip rings or telemetry. But the vibrational level provided to the motor by the rotor can be measured by instrumenting its bearings.

\subsection{PWM CONVERTER}

The pulse width modulation (PWM) converter has the function of converting DC voltage from the battery to AC sinusoidal waveform to the motor, by controlling the width of pulses of voltage that is provided to the motor. It switches on and off power inverters in determined switching frequencies, which can vary from 2 to $15 \mathrm{kHz}$. This should result in a pure sine wave, but non-uniformities on the magnetic field and winding distribution causes this signal to have harmonic distortions. These nonsinusoidal (current and voltage) waveform profiles excite the motor's lamination, and the consequence is a disturbing tonal noise [19].

This acoustic distortions can be seen on Figure 8, which refers to another motor tested, with the switching frequency of $10 \mathrm{kHz}$. It is clear that this frequency component remains, independent of the speed of the motor. But another interesting phenomena happens as well, which was not seen in usual ICE measurements: offset harmonic orders, whose starting point is on the switching frequency, with positive and negative components.

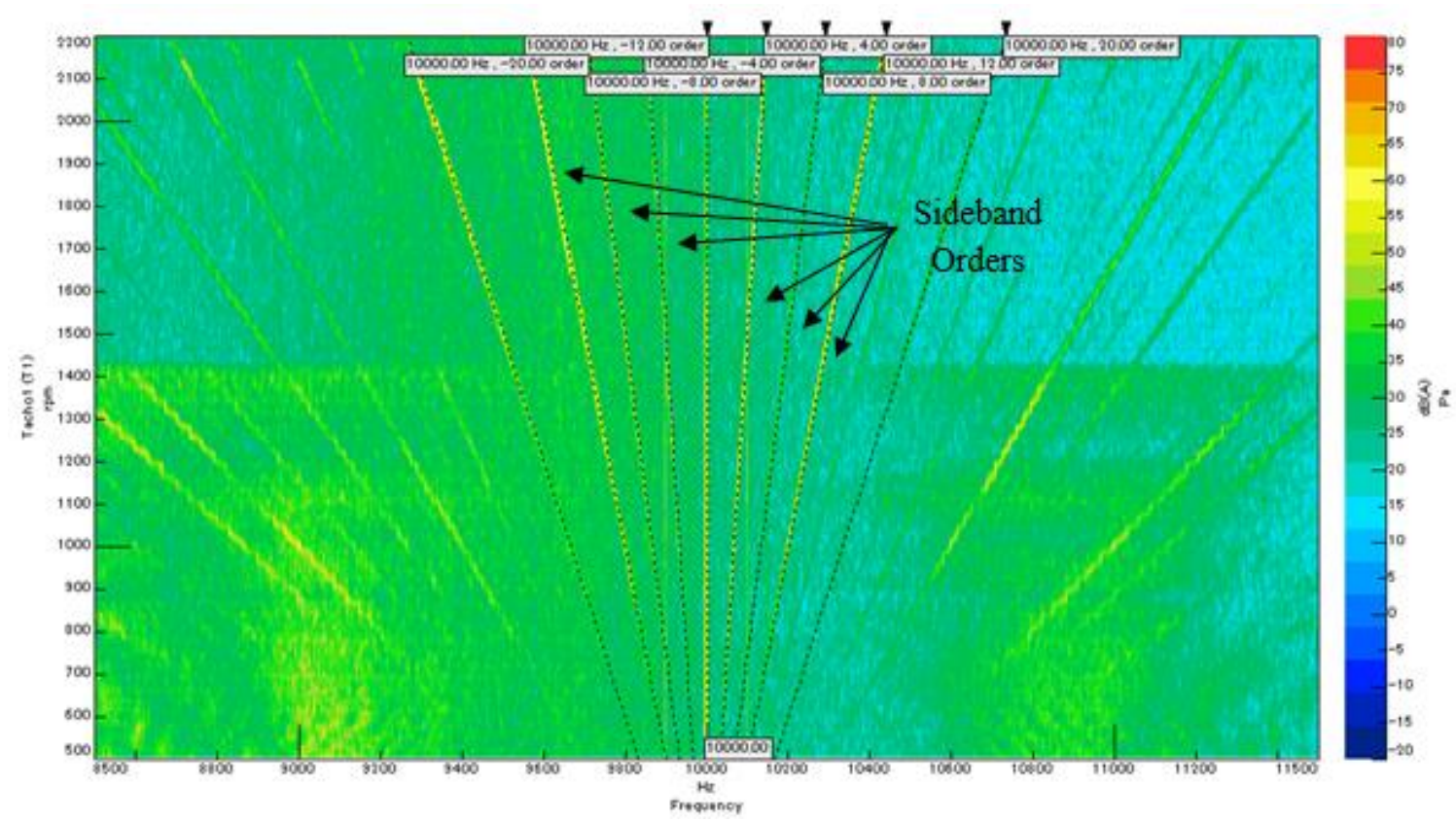

Figure $8-10 \mathrm{kHz}$ Switching Frequency and its Harmonic Orders 
Figure 9 and 10 show the interference of the PWM converter on the current of the machine when it is turned on, making the harmonic distortions appear.
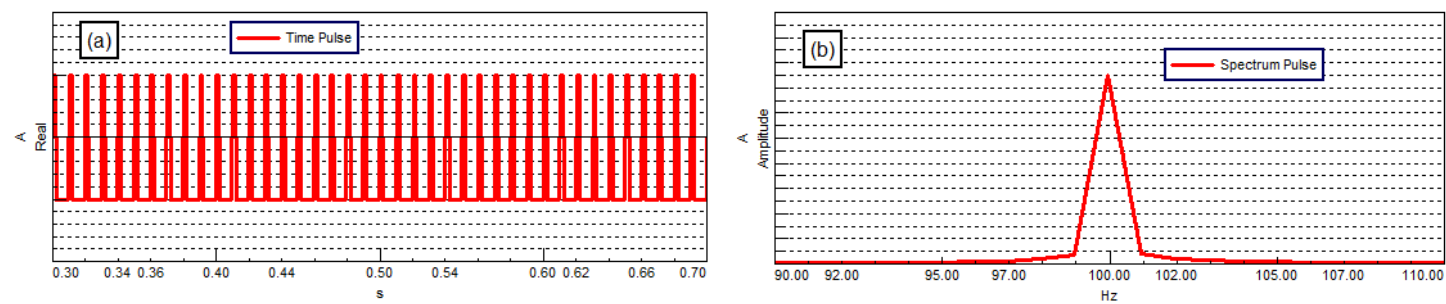

Figure 9 - Current (Ampere) data with no Pulse Width Modulation.

Left: Current Time data. Right: Current FFT data.
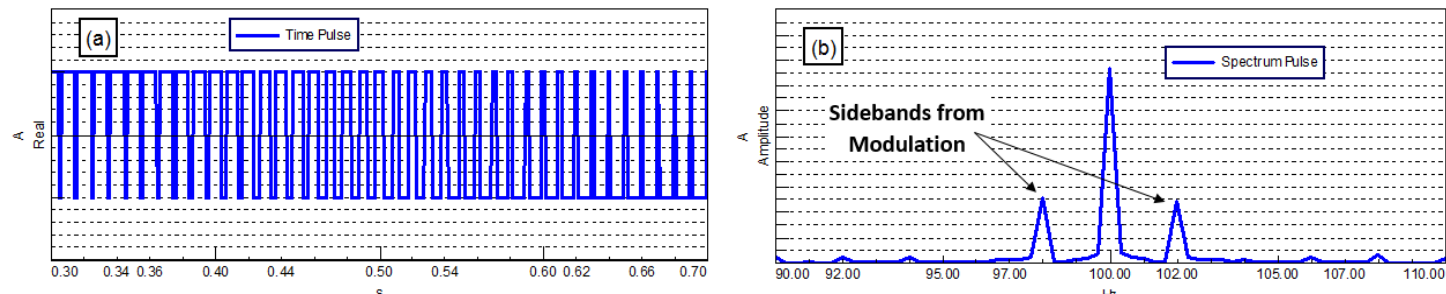

Figure 10 - Current (Ampere) data with Pulse Width Modulation.

Left: Current Time data. Right: Current FFT data.

Making a comparison between electric current and vibration, it can be seen that the order 12 of the vibration data has high correlation with the order 12 of the rated output PN (Positive-Negative) Current from battery, as can be seen in Figure 11. This measurement was made with the constant speed of $1000 \mathrm{rpm}$, and the vibration measured on the motor outer surface.

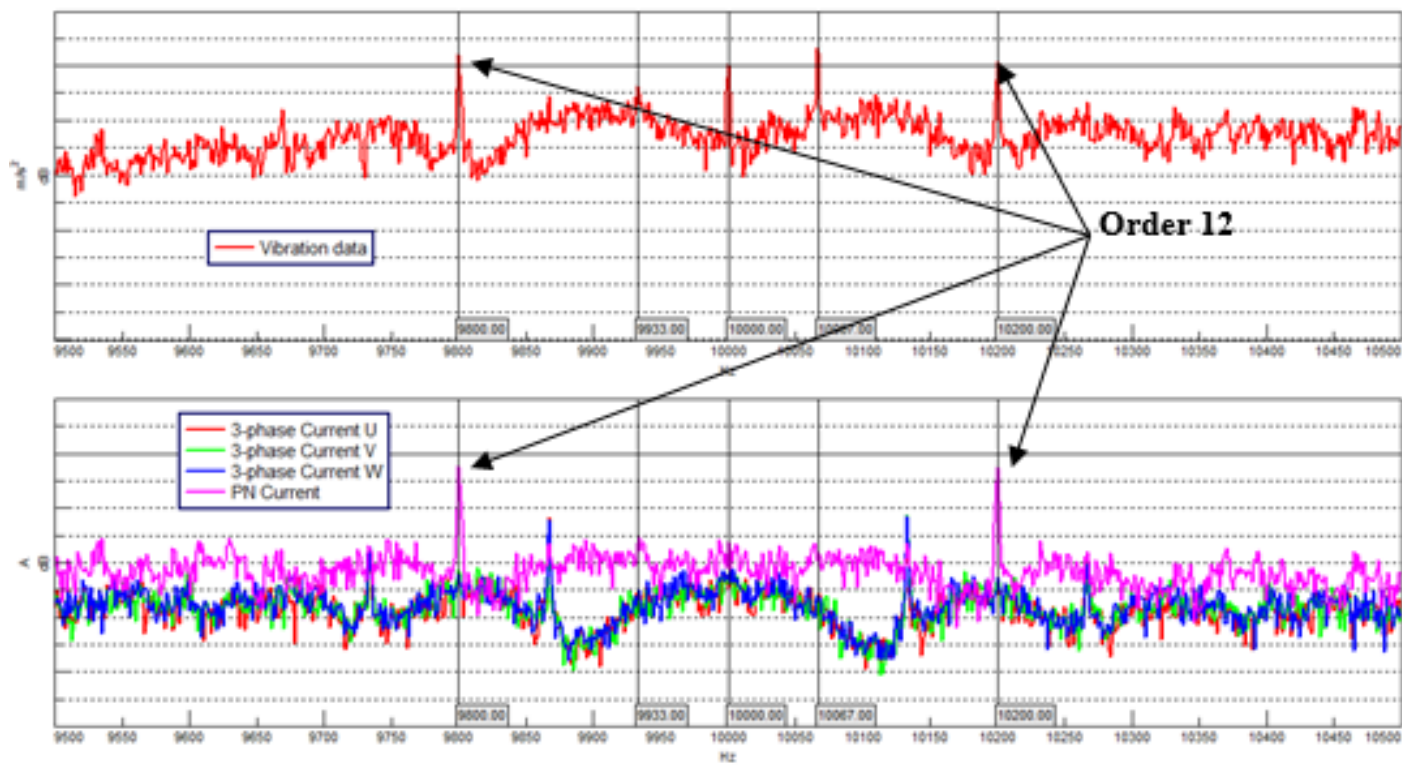

Figure 11 - Vibration data peaks at Order 12 found also on rated output PN Current from Battery

This same trend can be seen comparing noise and vibration, as shown in Figure 12. 


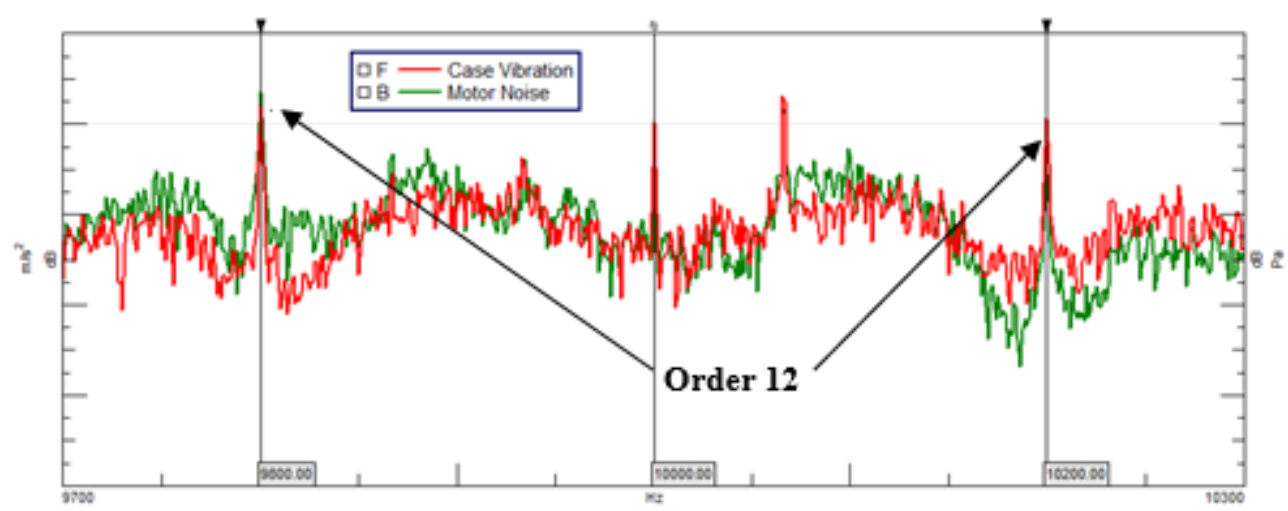

Figure 12 - Comparison between Motor Noise and Case Surface Vibration

All of this indicates the influence that the power electronics have on the acoustic perception of the motor, and the necessity to correctly design and simulate its behavior. The same study mentioned before [19] present strategies to mitigate this issue, such as utilizing high switching frequency (sometimes limited due hardware design and applications) which is less perceptible to frequency range, or implement gradual and discrete variation of the switching frequency during run-up.

\section{OTHER TOPICS ON ELECTRIC MOTOR TEST AND INSTRUMENTATION}

One topic that was seen on the last section is the necessity of not only measuring vibration on the machine components and its acoustic response, but also the current provided to the machine, to better understand the effect of power electronics on the vibrational and acoustic behavior. By experience, not having this data can make it harder to differentiate mechanical and electromagnetic response of motor operation from electric and electronics interference.

Another topic is the use of proper instrumentation for high frequency measurements. It is necessary to choose sensors, especially accelerometers and shakers, which can provide good data acquisition and excitation in higher frequencies. All sensors mentioned on item 2.1. were chosen because of their capability of providing reliable vibrational data up to $10 \mathrm{kHz}$.

Also, high frequency measuring capability can be achieved if the transducer is properly fixed normal to the surface of the structure, providing high stiffness contact between the two components. Therefore, it is very important to make the correct choice of the installation location of transducers, especially accelerometers [20]. There are different ways to attach the transducers to the surface of the test structure, some more convenient than others. Most miniature accelerometers can be attached to the structure using only an adhesive mounting. However, no adhesive is as rigid as a mounting stud, and the more adhesive joints between the test structure and the accelerometer, the greater the degradation of the transmissibility. Therefore, the cured adhesive stiffness is critical to the overall measurement performance. In addition, electrical insulation between the surface and the accelerometer must be provided. This electrical insulation is needed to help reduce noise and measurement errors. Alternatively, special insulation bases are used, for example built in bakelite. Although the use of insulation bases minimizes measurement noise, they can generate high frequency amplitude errors. In order to have a connection with adequate stiffness between the 
accelerometer and the motor structure, required to obtain the highest possible frequency response, the accelerometers were fixed at selected locations on the flat-surface structure using a very thin layer of glue. As a way to test the electrical insulation, a multimeter was used to ensure that the resistance was infinite. Figure 13 shows the improvement of the coherence function measured at the same site of the structure during impact testing, fixing the accelerometer properly.
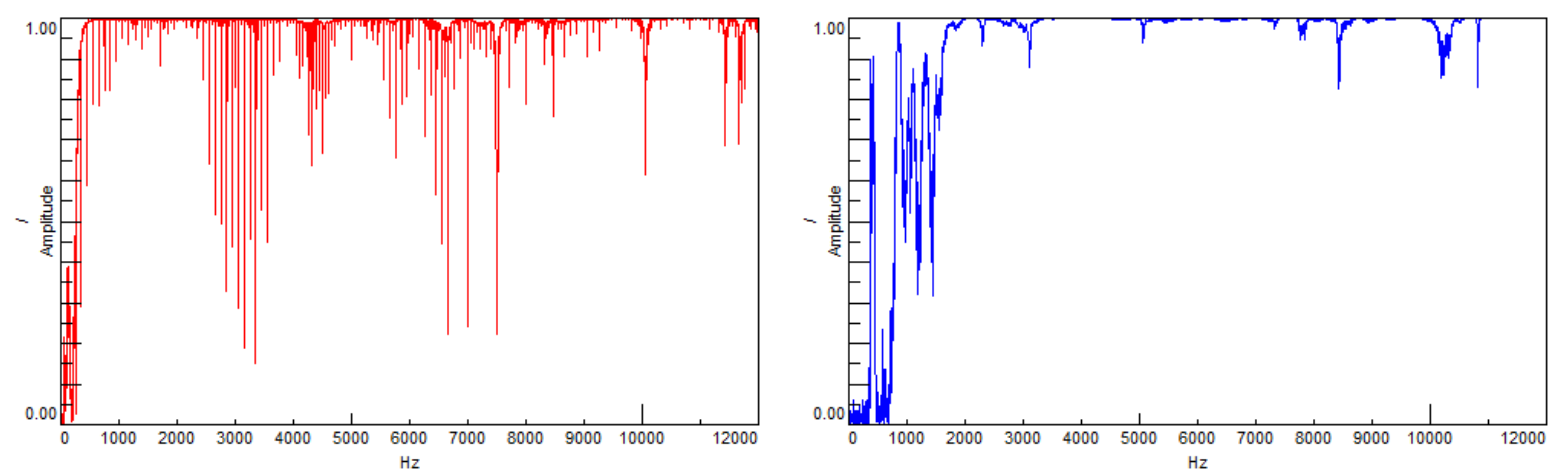

Figure 13 - Good coherence (blue curve) after correct fixation of the accelerometer. The red curve shows a bad insulation at the same point of the structure.

\section{CONCLUSION}

This work was made with the purpose to show some of the differences in the NVH perspective that electric motors present in comparison to IC engines, in order to bring to the Brazilian engineering community the different challenges the unavoidable insertion of electric and hybrid vehicles will bring to this market. Although the overall noise pressure level is smaller, higher frequencies and tonal harmonics can present also and unpleasant experience to the customer, therefore their main sources, such as electromagnetic excitations on the stator and its natural frequencies influence, rotor vibration and power electronics harmonic distortion, and some strategies to mitigate them were presented. Topics on best practices of EV test and instrumentation were also discussed, such as measurement of the current provided to the motor, sensor selection and proper fixation.

\section{ACKNOWLEDGMENTS}

The results presented in this paper are part of a project that has received funding from the European Union's Horizon 2020 research and innovation programme under project name ESPESA and grant agreement No 692224. 


\section{REFERENCES}

[1] DIJR, M.; ORSATO, R. J.; KEMP, R. The emergence of an electric mobility trajectory. Energy Policy. 2013. 52, 135-145.

[2] T\&E, CO2 Emissions from New Cars. 2008.

[3] MESSAGIE, M.; LEBEAU, K.; COOSEMANS, T.; MACHARIS, C. et al. Environmental and financial evaluation of passenger vehicle technologies in Belgium. Sustainability (Switzerland). 2013. 5(12), 5020-5033.

[4] RODRIGUES, L. Com redução do IPI prevista, carros elétricos ganham mais energia. Correio Braziliense, March 2018, available at https://www.correiobraziliense.com.br/app/noticia/economia/2018/03/15/internas_economia,6 66210/com-reducao-do-ipi-prevista-carros-eletricos-ganham-mais-energia.shtml. Accessed May 2018.

[5] REGHIN, M. Brasil tem potencial para vender 150 mil carros elétricos ao ano. Época Negócios. $\quad$ February $2018 . \quad$ Available at https://epocanegocios.globo.com/Tecnologia/noticia/2018/02/brasil-tem-potencial-paravender-150-mil-carros-eletricos-ao-ano.html. Accessed May 2018.

[6] DElgado, F.; COSTA, J. E. G.; FEBraro, J.; SILVA, T. B. Carros elétricos. Cadernos FGV Energia, N 7. May 2017. ISSN 2358-5277.

[7] GOETCHIUS, G. Leading the Charge - The Future of Electric Vehicle Noise Control. Sound \& Vibration, April 2011. Available at: http://greggoetchius.com/1104goet.pdf. Accessed May 2018.

[8] FARIA, C. T.; MONGELlAZ, R.; OPREA, C.; BOON, F. et al. Design process of advanced reluctance machines for electric vehicle applications. 2015 Institute of Electrical and Electronics Engineers (IEEE) Vehicle Power and Propulsion Conference (VCCP). DOI:10.1109/VPPC.2015.7352928. October 2015.

[9] GALCO INDUSTRIAL ELECTRONICS. AC Motor diagrams - basic stator and rotor operations. Available at https://www.galco.com/comp/prod/moto-ac.htm. Accessed May 2018.

[10] PILLAY, P.; OMEKANDA, A. M. Low-vibration design of switched reluctance motors for automotive applications using modal analysis. IEEE Trans. Ind. Appl., 2003, 39(4), 971-977.

[11] SARRAZIN, M.; GILLIJNS, S.; ANTHONIS, J.; JANSSENS, K. et al. NVH analysis of a 3 phase 12/8 SR motor drive for HEV applications. 2013 World Electric Vehicle Symposium and Exhibition (EVS27). Barcelona, Spain. DOI:10.1109/EVS.2013.6914767, November 2013

[12] HENDERSHOT, J.R. Causes and sources of audible noise in electric motors. 1993. Available

at http://www.jimhendershot.com/Jim_Hendershot/Articles_files/causes\%26sources\%20of\%20a udible\%20noise\%20in\%20elec\%20motors.pdf. Accessed May 2018.

[13] CHAUVICOURT, F; ORLANDO, S.; DESMET, W.; GYSELINCK, J. J. C. et al. Experimental study on the impact of the number of laminas on the dynamics behavior of an electric machine stator. Topics in Modal Analysis \& Testing, Volume 10: Proceedings of the 34th IMAC, A Conference and Exposition on Structural Dynamics. 2016 (pp.73-79,). ISSN:2191-5644, DOI:10.1007/978-3-319-30249-2_5. May 2016.

[14] CHAUVICOURT, F; ORLANDO, S.; DESMET, W.; GYSELINCK, J. J. C. et al. Experimental and numerical validation of laminated structure dynamics from a switched reluctance machine stator. International Conference on Structural Engineering Dynamics - ICEDyn, Lagos, Portugal, June 2015. 
[15] CHAUVICOURT, F.; FARIA, C. T.; GYSELINCK, J. J. C.; DESMET, W. Validation of homogenization technique used for accurate predictions of laminated structures' mechanical behavior. 27th ISMA - International Conference on Noise and Vibration Engineering. Leuven, Belgium. September 2016.

[16] SANTOS, F. L. M.; ANTHONIS, J.; NACLERIO, F.; GYSELINCK, J. J. C. et al. Multiphysics NVH modeling: simulation of a switched reluctance motor for an electric vehicle. IEEE Transactions on Industrial Electronics, Vol. 61 (1):469-476. January 2014.

[17] CHAUVICOURT, F; BALLWEG, M; DESMET, W.; VAN DER AUWERAER, H.; FARIA, C. T. Experimental study on the rotor dynamics influence upon the modal characteristics of an induction machine. Topics in Modal Analysis \& Testing, Volume 10. Springer. DOI:10.1007/978-3-319-54810-4_18. March 2017.

[18] BARTAlOTTA, A.; CHAUVICOURT, F.; FARIA, C. T. Study on the effect of the rotor dynamics on the vibro-acoustic response of electric machines. NAFEMS UK Conference 2016. Telford, United Kingdom. June 2016.

[19] SARRAZIN, M.; JANSSENS, K.; VAN DER AUWERAER, H. Influence of inverter PWM control schemes on noise signatures of electric powertrains. 20th International Congress on Sound \& Vibration - ICSV20. Bangkok, Thailand. July 2013.

[20] EWINS, D. J. Modal Testing: Theory, Practice and Application. Second Edition. Research Studies Press Ltd., 2000. 